\title{
PENGARUH IMPLEMENTASI PELAYANAN INFORMASI OBAT TERHADAP TINGKAT KEPUASAN PASIEN DI APOTEK
}

\author{
Musyarofah $^{1}$, Hanari Fajarini*2, Rifqi Ferry Balfas ${ }^{3}$, Efi Dence ${ }^{4}$ \\ 1,2,3,4 Program Studi D3 Farmasi Fakultas Ilmu Kesehatan Universitas Muhadi Setiabudi \\ e-mail: ${ }^{1}$ mus.musya94@gmail.com, ${ }^{* 2}$ hanari.fajarini@gmail.com, ${ }^{3}$ rifqi.ferry.balfas@ gmail.com, \\ 4efi.dence@gmail.com
}

\begin{abstract}
ABSTRAK
Pada pelayanan kesehatan, obat merupakan komponen yang penting karena diperlukan dalam sebagian besar upaya kesehatan untuk menghilangkan gejala dari suatu penyakit, mencegah penyakit, serta dapat menyembuhkan penyakit. Tetapi di lain pihak obat dapat menimbulkan efek yang tidak diinginkan apabila penggunaannya tidak tepat. Pelayanan kefarmasian pada saat ini telah bergeser orientasinya dari pelayanan obat (drug oriented) menjadi pelayanan pasien (patient oriented)yang mengacu pada asuhan kefarmasian(pharmaceutical care). sehingga dapat menghindari risiko terjadinya medication error serta memenuhi kebutuhan pasien dan kepuasan pasien dalam memperoleh pengobatan atau pemberian obat dari apoteker. Penelitian ini membahas tentang implementasi pelayanan informasi obat kepada pasien yang ada di Apotek Sawojajar dan kepuasan pasien dalam menerima pelayanan informasi obat oleh petugas apotek maupun apoteker.Hasil penelitian yang telah dilakukan menunjukan bahwa hasil analisis diperoleh nilai P_value sebesar 0,024 $(p<0,05)$ sehingga terdapat hubungan yang signifikan antara implementasi PIO dan kepuasan pasien. Metode penelitian yang penulis ambil adalah penelitian deskriptif analitik yang akan menggunakan quisioner untuk dapat mengambil pernyataan pasien sebagai bahan uji dalam penelitian.Dengan adanya pemberian pelayanan informasi obat dapat meningkatkan kualitas dan kuantitas mutu apotek dalam pelayanan informasi obat kepada pasien, memberikan pelayanan informasi obat yang benar, jelas dan tepat, mengetahui kelemahan dan keunggulan apotek dalam segi pelayanan informasi obat.
\end{abstract}

Kata Kunci : pelayanan informasi obat, (PIO), pelayanan kefarmasian, kepuasan pasien

\section{ABSTRACT}

In health services, drugs is an important component because it is required in most health efforts to eliminate the symptoms of a disease, prevent disease, and cure the disease. But drugs can cause medication errors if it is used inappropriately. Pharmaceutical services at this time has shifted the orientation from drug oriented to patient oriented which refers to pharmaceutical care to avoid the risk of medication errors and meet the needs of patients and patient satisfaction in obtaining treatment or administration of drugs from the pharmacist. This study discusses the implementation of drug information services in Sawojajar Pharmacy and satisfaction of patients on the drug information services by the pharmacist. Results of the research that has been conducted shows that the analytical results obtained $P$ value of 0.024 ( $p<0.05)$. It is significant correlation between the drug information services and patient satisfaction. The research method is descriptive analytic that will use the questionnaires to take the statement of the patient. With the provision of drug information services to improve the quality of pharmacy, provide the correct drug information service, clearly and precisely, knowing the weaknesses and advantages of pharmacies in terms of drug information services.

Keyword: drug information service, pharmaceutical care, patients satisfactio 


\section{PENDAHULUAN}

Obat merupakan salah satu komponen yang sangat penting dalam upaya pencegahan penyakit, menghilangkan gejala dari suatu penyakit, serta dapat menyembuhkan penyakit. Namun, obat itu sendiri dapat menimbulkan efek yang tidak diinginkan apabila penggunaannya tidak tepat. Oleh sebab itu, penyediaan informasi obat yang benar, objektif dan lengkap akan sangat mendukung dalam pemberian pelayanan kesehatan yang terbaik kepada masyarakat sehingga dapat meningkatkan kemanfaatan dan keamanan penggunaan obat.

Sistem pelayanan kefarmasian pada saat ini telah berubah orientasinya dari pelayanan obat (drug oriented) menjadi pelayanan pasien (patient oriented) yang mengacu pada asuhan kefarmasian (pharmaceutical care). [1] Kegiatan pelayanan kefarmasian awalnya hanya berfokus pada pengelolaan obat sebagai komoditi, namun pada saat ini bergesr menjadi pelayanan yang komprehensif yang bertujuan untuk meningkatkan kualitas hidup dari pasien. Perubahan orientasi tersebut, apoteker/asisten apoteker sebagai tenaga farmasi dituntut untuk meningkatkan pengetahuan, keterampilan, dan perilakunya agar dapat berinteraksi langsung dengan pasien. Bentuk interaksi tersebut antara lain adalah melaksanakan pemberian informasi, monitoring penggunaan obat untuk mengetahui tujuan akhirnya sesuai harapan dan terdokumentasi dengan baik. Dalam dunia farmasi seorang farmasis harus bisa memahami dan menyadari kemungkinan terjadinya kesalahan pengobatan (medication error) dalam proses pelayanan [2].

Pelayanan informasi obat adalah kegiatan penyediaan dan pemberian informasi, rekomendasi obat yang independen, akurat, komprehensif dan terkini oleh apoteker kepada pasien dan masyarakat yang membutuhkan. Tujuan informasi obat adalah meningkatkan keberhasilan terapi, memaksimalkan efek terapi dan meminimalkan resiko efek samping. Manfaat pelayanan informasi bagi apoteker adalah menjaga citra profesi sebagai bagian dari pelayanan kesehatan, mewujudkan pelayanan kefarmasian sebagai tanggung jawab profesi, menghindari medication error dan pelayanan untuk menarik pasien dalam upaya memasarkan pelayanan. Informasi obat adalah setiap data atau pengetahuan obyektif diuraikan secara ilmiah dan terdokumentasi mencakup farmakologi, toksikologi, dan farmakoterapi obat.

Pelaksanaan pelayanan informasi obat merupakan kewajiban farmasis yang diatur dalam Peraturan Menteri Kesehatan RI Nomor 73 Tahun 2016 tentang Standar Pelayanan Kefarmasian di Apotek. Kegiatan pelayanan yang dilakukan oleh seorang farmasis dalam memberi informasi harus secara akurat, tidak bias dan terkini kepada tenaga kesehatan lainnya dan juga pasien. Pada penggunaan obat memiliki cara dan teknik yang berbeda-beda, oleh karena itu seorang farmasis hendaknya selalu memberikan informasi kepada setiap pasien bagaimana cara mereka mempergunakan atau meminum obat serta informasi mengenai aturan pakai obat dan efek samping yang kemungkinan timbul akibat pemakaian obat tersebut. Dengan pemberian informasi tersebut diharapkan dapat terjalin hubungan yang baik sehingga dapat mengurangi atau menghindari kemungkinan terjadinyna kesalahan penyerahan atau pemakaian obat [3].

Fakta yang terjadi saat ini, yaitu dimana belum semua pasien tahu dan sadar akan apa yang harus dilakukan tentang obat yang mereka gunakan. Sehingga, untuk mencegah penyalahgunaan, dan adanya interaksi obat yang tidak dikehendaki, maka pelayanan infomasi obat merupakan hal yang sangat diperlukan. Terlebih lagi belum semua pasien mendapatkan informasi yang memadai dan juga pengetahuan tentang obat yang digunakan belum semuanya diketahui, serta adanya obat-obat tertentu yang sangat memerlukan perhatian.

Apotek memegang teguh dalam pelayanan informasi obat yang jelas dan tepat kepada pasien. Maka akan memberikan kepuasan tersendiri bagi pasien dan dapat memberikan secara tidak langsung konseling obat yang aman dalam penggunaannya, sehingga menjadikan persepsi konsumen yang baik kepada apotek. Pasien juga akan merasa percaya dan nyaman dalam pelayanan obat, untuk apotek sendiri memperoleh pencitraan yang baik yang condong ke patient oriented, sehingga pasien yang berobat menjadi bertambah dan mempunyai kepercayaan terhadap Apotek tersebut [4].

Implementasi pelayanan informasi obat (PIO) sangat penting bagi pasien agar dapat mengatasi masalah penyalahgunaan obat yang dilakukan oleh pasien selama ini. Contoh kasus 
penyalahgunaan obat yang ada ketika pelayanan informasi obat tidak disampaikan secara tepat seperti:

1) Ketika pasien A menggunakan tetes telinga untuk mengobati tetes mata yang seharusnya pasien A menggunakannya untuk mengobati telinganya.

2) Pasien B meminum obat antacid sesudah makan yang seharusnya obat antacid itu diminum sebelum makan dan harus dikunyah terlebih dahulu untuk mengoptimalkan kerja obat tersebut.

3) Pasien $\mathrm{C}$ meminum obat furosemide pada malam hari sehingga pasien tersebut mengganggu waktu tidur pasien akibat kencing terus menerus, yang seharusnya obat furosemide itu disarankan untuk diminum pada pagi hari agar pasien tidak merasa terganggu dari efek setelah peminuman obat furosemide tersebut.

4) Seoarang anak kecil yang memakan vitamin tablet hisap terlalu banyak dalam satu hari seperti ia memakan permen sehingga anak itu mengalami over dosis dan efek yang timbul perut anak itu merasa sakit dan mengalami diare.

Kepuasan pasien dapat diartikan sebagai sebuah pemahaman mengenai kebutuhan dan keinginan pasien yang merupakan salah satu hal penting yang dapat mempengaruhi kepuasan pasien. Apabila pasien merasa puas mereka akan terus melakukan pemakaian terhadap jasa pilihannya, tetapi jika pasien merasa tidak puas mereka akan memberitahukan kepada orang lain tentang pengalaman buruknya. Untuk menciptakan kepuasan pasien, apotek harus menciptakan dan mengelola suatu sistem untuk memperoleh pasien yang lebih banyak dan kemampuan untuk mempertahankan pasiennya.

Kepuasan pasien dalam menggunakan jasa Apotek memiliki arti bahwa pasien atau pasien mengerti cara pemakian obat atau membeli produk tertentu di Apotek. Proses informasi dan komponen kepuasan secara bersama-sama akan menjadi elemen yang penting sebagai kepuasan pasien. Dapat disimpukan kepuasan pasien menggunakan jasa Apotek merupakan informasi dan komponen pengetahuan serta keinginan yang timbul dalam diri pasien untuk membeli obat di Apotek dan mengerti aturan dan pemakian obat tersebut. [5]

Berdasarkan dari pengamatan pada pasien Apotek Sawojajar selama 1 minggu terdapat 210 pasien yang datang untuk berobat, dari 210 pasien baru $70 \%$ pasien yang belum mengetahui tentang PIO. oleh karena itu penulis tertarik untuk melakukan penelitian terhadap pasien di Apotek Sawojajar Brebes dengan mengambil 50 pasien sebagai sampel untuk mewakili semua pasien Apotek dalam Penelitian Pengaruh Implementasi Pelayanan Informasi Obat (PIO) Terhadap Tingkat Kepuasan Pasien Di Apotek Sawojajar.

\section{METODE PENELITIAN}

\subsection{Alat dan Bahan}

Alat ukur untuk instrumen penelitian yang digunakan oleh peneliti adalah kuesioner. Kuesioner merupakan alat ukur dengan bentuk pertanyaan. Kuesioner yang digunakan dalam hal ini yaitu kuesioner terbuka. Kuesioner terbuka disajikan dalam bentuk sederhana sehingga responden dapat memberikan isian sesuai dengan kehendak atau keadaannya. [6]

\subsubsection{Kuesioner Implementasi}

Kuesioner yang berisikan pertanyaan tertutup mengenai implementasi PIO di Apotek yang merupakan bagian dari variabel Independen. Skala Implementasi disusun berdasarkan pelayanan petugas Apotek.Penilaian pada kuesioner ini menggunakan kategori jenjang (nominal).Tujuan kategori ini adalah menempatkan individu ke dalam kelompok-kelompok dalam perbedaan karakteristik suatu objek dari karekateristik lainnya, contohnya ya dan tidak. Penelitian kuesioner ini membagi 3 kategori yaitu ya dan tidak dengan ketentuan sebagai berikut : Baik 76-100 \%; Cukup 57-75\%; Kurang $\leq 56 \%$.

\subsubsection{Kuesioner kepuasan}

Kuesioner yang berisikan pertanyaan terbuka mengenai kepuasan pasien berobat di Apotek yang merupakan bagian dari variabel dependen. Skala kepuasan disusun berdasarkan implementasi Pelayanan Informasi Obat.Penilaian pada kuesioner ini menggunakan kategori jenjang (nominal). Tujuan kategori ini adalah menempatkan individu ke dalam kelompok-kelompok dalam perbedaan karakteristik suatu objek dari 
karekateristik lainnya, contohnya sangat puas, puas, dan tidak puas. Penelitian kuesioner ini membagi 3 kategori yaitu puas dan tidak puas, dengan ketentuan sebagai berikut: Baik $76-$ $100 \%$; Cukup $57-75 \%$; Kurang $\leq 56 \%$.

\subsubsection{Uji Validitas dan Reabilitas}

Salah satu instrument yang digunakan dalam penelitian ini adalah kuesioner.Untuk mendapatkan data yang valid dan reliabel maka kuesioner tersebut harus diuji validitas dan reabilitas.Pelaksanaan uji validitas dan reabilitas dilaksanakan pada responden yang tidak menjadi sampel dalam penelitian sebanyak 50 responden.

\subsection{Jalannya Penelitian}

\subsubsection{Desain Penelitian}

Jenis penelitian ini adalah salah satu bentuk rancangan penelitian deskriptif analitik dengan menggunakan desain cross sectional yaitu penelitian non-eksperimental dalam rangka mempelajari dinamika korelasi antar faktor-faktor Pelayanan Informasi Obat (PIO) dengan dampak kepuasan pasien dengan model pendekatan point time. [7] Dalam hal ini menganalisis tentang pengaruh implementasi Pelayanan Informasi Obat (PIO) terhadap tingkat kepuasan pasien.

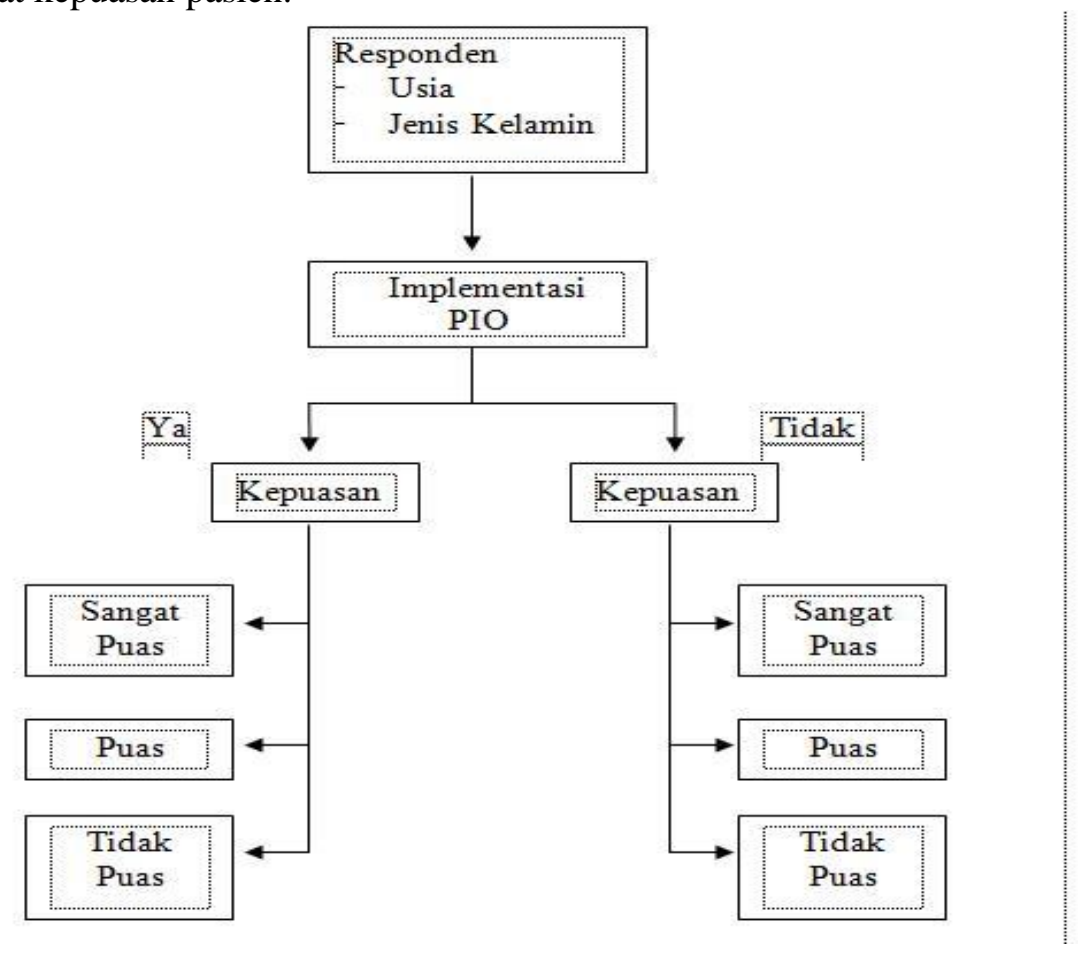

\subsubsection{Tempat dan Waktu Penelitian}

Penelitian dilaksanakan di Apotek Sawojajar, Desa Sawojajar, Kecamatan Wanasari, Kabupaten Brebes

\subsubsection{Populasi dan Sampel Penelitian}

Populasi (universe) adalah keseluruhan unit analisis dan karakterisitik yang akan diduga. [8] Populasi pada penelitian ini adalah pasien yang datang berobat ke Apotek Sawojajar Brebes, rata-rata jumlah pasien yang datang berjumlah 210 pasien dalam 1 minggu. Sampel merupakan bagian-bagian dari populasi yang akan diteliti atau sebagian jumlah dari karakteristik yang dimiliki oleh populasi.[8] Teknik pengambilan sampel menggunakan teknik total sampling, yaitu teknik penentuan sampel dengan mengambil seluruh anggota populasi sebagai responden atau sampel.[9] Dengan demikian, peneliti mengambil sampel dari seluruh pasien yang datang berobat ke Apotek Sawojajar Brebes. Jumlah sampel dalam penelitian ini adalah 50 orang.

\subsubsection{Cara Pengambilan Sampel}

Untuk mendapatkan data sesuai dengan fokus penelitian ini, maka peneliti menentukan responden dengan kriteria sebagai berikut : 
1) Kriteria Inklusi

Kriteria inklusi adalah karakteristik umum subjek penelitian dari suatu populasi suatu target dan terjangkau akan diteliti. Adapun kriteria inklusi sampel kelompok kasus yang akan diteliti adalah :

- Pasien yang datang berobat ke Apotek Sawojajar Brebes

- Bersedia menjadi responden.

2) Kriteria eksklusi

Kriteria eksklusi adalah keadaan yang menyebabkan subjek memenuhi kriteria inklusi namun tidak dapat diikutsertakan dalam penelitian.

- Pasien yang hanya membeli obat bebas

- Ibu yang tidak bisa membaca dan menulis.

\subsubsection{Variabel Penelitian}

- Pasien atau keluarga yang berasal dari pegawai Apotek tersebut.

Variabel penelitian adalah sesuatu yang digunakan sebagai ciri, sifat dan ukuran yang dimiliki atau didapatkan oleh satuan penelitian tentang sesuatu konsep pengertian tertentu. [8] Jenis variabel penelitian yang sering digunakan yaitu : Variabel bebas (independent variable) adalah variabel yang menjadi sebab atau berubahnya dependent variable.[9] Variabel bebas dalam penelitian ini yaitu pengaruh implementasi pelayanan informasi obat (PIO). Variabel terikat (dependent variable) adalah variabel yang dipengaruhi atau yang menjadi akibat karena adanya variabel bebas, dan variabel ini sering disebut variabel respon. Variabel terikat dalam penelitian ini adalah tingkat kepuasan pasien di Apotek Sawojajar Brebes.

\subsection{Analisis Data}

Data yang telah diperoleh selanjutnya dianalisis. Analisis data dilakukan untuk menunjang pembuktian hipotesis. Proses analisis data dimulai dengan menelaah seluruh data yang diperoleh melalui kuesioner. Langkah - langkah analisis data dilakukan secara bertahap, yaitu :

\subsubsection{Analisis Univariat}

Analisis data univariat bertujuan untuk menjelaskan atau mendeskripsikan karakteristik setiap variabel penelitian.Pada umumnya dalam analisis ini hanya menghasilkan distribusi dan presentase dari setiap variable.[8] Analisis univariat untuk masing-masing variabel, dimana data yang bersifat kategorik yaitu umur pasien, jenis kelamin, disajikan dalam bentuk frekuensi dan presentase.Semua data di analisis dengan bantuan software statistik dan disimpulkan secara deskriptif.

\subsubsection{Analisis Bivariat}

Analisis bivariat adalah analisis yang menghubungkan dua variabel yaitu variabel bebas dan variabel terikat.[10] Analisis bivariat dalam penelitian ini yaitu mengetahui pengaruh implementasi PIO terhadap tingkat kepuasan pasien diApotek Sawojajar Brebes.Untuk mencari hubungan antar variabel digunakan uji Chi Square dengan bantuan program SPSS dan Excel.

\section{HASIL DAN PEMBAHASAN}

\subsection{Hasil Penelitian}

\subsubsection{Analisis Univariat}

Tabel I. Deskripsi Karakteristik Responden Pasien

\begin{tabular}{|c|c|c|}
\hline $\begin{array}{c}\text { Variable } \\
\text { Responden Pasien }\end{array}$ & $\begin{array}{c}\text { Frekuensi } \\
(\mathbf{n = 4 2})\end{array}$ & $\begin{array}{c}\text { Persentase } \\
(\boldsymbol{\%})\end{array}$ \\
\hline Umur & 18 & \\
$-18-25$ & 20 & 36,0 \\
$-25-35$ & 12 & 20,0 \\
- > 35 & & \\
\hline Jenis kelamin & 12 & 24,0 \\
- Pria & 38 & 76,0 \\
- Wanita & \multicolumn{2}{|l}{} \\
\hline
\end{tabular}


Berdasarkan tabel I responden terbanyak adalah umur 25 - 35 yaitu sebanyak 20 pasien $(40,0 \%)$ yang datang berobat ke Apotek Sawojajar.

Tabel II. Deskripsi Implementasi Dan Kepuasan Pasien

\begin{tabular}{|c|c|c|}
\hline Variable & $\begin{array}{c}\text { Frekuensi } \\
(\mathbf{n = 4 2})\end{array}$ & Persentase (\%) \\
\hline Implementasi & 7 & 14,0 \\
- Baik & 26 & 52,0 \\
- Cukup & 17 & 34,0 \\
- Kurang & & \\
\hline Kepuasan & 9 & 18,0 \\
- Sangat Puas & 28 & 56,0 \\
- Puas & 13 & 26,0 \\
- Tidak Puas & & \\
\hline
\end{tabular}

Dari tabel II dapat dilihat bahwa implementasi sudah terlaksana cukup baik yaitu sebanyak 26 responden atau sebesar 52,0\%.

\subsubsection{Analisis Bivariat}

Tabel III. Hasil Uji Crosstabe Pengaruh Implementasi PIO Terhadap Kepuasan pasien di Apotek Sawojajar Brebes.

\begin{tabular}{|c|c|c|c|c|c|c|c|c|c|}
\hline \multirow{3}{*}{$\begin{array}{c}\text { Variable } \\
\text { Implementa } \\
\text { Si }\end{array}$} & \multicolumn{6}{|c|}{ Kepuasan } & \multirow{2}{*}{\multicolumn{2}{|c|}{ Total }} & \multirow[t]{2}{*}{ P. Value } \\
\hline & \multicolumn{2}{|c|}{$\begin{array}{c}\text { Sangat } \\
\text { Puas }\end{array}$} & \multicolumn{2}{|c|}{ Puas } & \multicolumn{2}{|c|}{ Tidak Puas } & & & \\
\hline & $\mathrm{N}$ & $\%$ & $\mathrm{~N}$ & $\%$ & $\mathrm{~N}$ & $\%$ & $\mathrm{n}$ & $\%$ & \\
\hline Baik & 2 & $\begin{array}{c}28, \\
6\end{array}$ & 3 & 42,9 & 2 & 28,6 & 7 & & \\
\hline Cukup & 6 & $\begin{array}{c}23, \\
1\end{array}$ & 10 & 38,5 & 10 & 38,5 & 26 & 100 & 0,024 \\
\hline Kurang & 1 & 5,9 & 15 & 88,2 & 1 & 5,9 & 17 & & \\
\hline Jumlah & 9 & $\begin{array}{c}18, \\
0\end{array}$ & 28 & 56,0 & 13 & 26,0 & 50 & 100 & \\
\hline
\end{tabular}

Tabel tabel III Menjelaskan bahwa implementasi PIO yang baik mempunyai kepuasan pasien sangat puas sebanyak $2(28,6 \%)$, kepuasan pasien puas sebanyak $3(42,9 \%)$ dan kepuasan pasien tidak puas sebanyak $2(28,6 \%)$. Pada implementasi PIO yang cukup dalam kepuasan pasien sangat puas sebanyak $6(23,1 \%)$ kepuasan pasien puas sebanyak $10(38,5$ $\%)$ dan kepuasan pasien tidak puas sebanyak 10 (38,5\%). Sedangkan pada implementasi PIO yang kurang dalam kepuasan pasien sangat puas sebanyak $1(5,9 \%)$, kepuasan pasien puas sebanyak $15(88,2 \%)$, dan kepuasan pasien tidak puas sebanyak $1(5,9 \%)$. Hasil analisis menunjukan nilai $P_{-}$value sebesar $0,024(\alpha \leq 0,05)$ sehingga terdapat hubungan yang signifikan antara implementasi PIO terhadap kepuasan pasien. 


\subsection{Pembahasan}

\subsubsection{Karakteristik Responden}

a. Umur Pasien

Berdasarkan hasil penelitian pada umur pasien yaitu sebagian besar berumur 25 sampai dengan 3 sebanyak $20(40,0 \%)$, dengan tingkat faktor umur yang cenderung merasakan keadaan yang harus melakukan pengobatan baik untuk mencegah atau pun berobat sehingga pada pasien dengan umur tersebut mulai rutin berobat salah satunya berobat ke Apotek Sawojajar. Sebagian besar pasien sudah mempunyai seorang anak, sehingga mereka datang ke apotek membawa anaknya untuk berobat. Pada usia 18 - 25 pasien berobat ketika pasien sudah merasa sakit dan membutuhkan obat barulah mereka datang berobat ke Apotek, sedangkan untuk pasien umur > 35 tahun cenderung mulai ketergantungan dengan berobat ke Apotek karena faktor kesehatan yang sudah mulai menurun dan memliki penyakit yang ketergantungan dengan obat seperti diabetes, hipertensi, asam urat, kolesterol tinggi dan masih banyak yang lainnya.

b. Jenis Kelamin

Berdasarkan hasil penelitian menunjukan sebagian responden pasien berjenis kelamin wanita sebanyak $36(75,0 \%)$. Jenis kelamin pasien merupakan salah satu karakteristik pasien mempengaruhi jumlah pasien yang datang berobat ke Apotek. Pasien wanita cenderung lebih sering datang ke Apotek baik untuk berobat diri sendiri maupun membawa anaknya untuk berobat.Didukung pula dengan Apoteker seorang wanita sehingga lebih banyak pasien wanita yang merasa nyaman untuk berobat.Pasien wanita pun cenderung lebih banyak melakukan konsultasi baik dengan Apoteker ataupun petugas Apotek, sehingga pasien wanita sebagian besar mengetahui dan menerapkan PIO (Pelayanan Informasi Obat). Sedangkan untuk pasien pria lebih jarang datang ke Apotek karena mereka cenderung malu bertanya ataupun melakukan konsultasi dengan Apoteker.sehingga banyak dari pasiem pria yang masih belum mengetahui tentang PIO (Pelayanan Informasi Obat) dalam Apotek dan dalam penggunaan obat. Pasien pria pun cenderung malas untuk sekedar berobat dan membeli obat ke Apotek. Sehingga pasien dengan jenis kelamin pria lebih sedikit dibandingkan dengan pasien wanita yang mendominasi Apotek Sawojajar.

\subsubsection{Implementasi}

Informasi yang didapatkan oleh sebagian besar konsumen baru sebatas harga obat, cara dan dan aturan pakai obat. Hal ini berarti pelayanan apotek di tiga kota tersebut masih berorientasi pada produk, belum berorientasi pada pasien. Padahal menurut standar pelayanan farmasi komunitas, semua informasi tersebut di atas seharusnya diberikan oleh apotek dan merupakan hak konsumen atau pasien.[4] Informasi yang lengkap dan jelas akan mengurangi risiko terjadinya medication error. Menurut penelitian yang dilakukan di 500 apotek di Amerika Serikat, kesalahan yang sering terjadi pada tahap dispensing antara lain adalah cara pemberian obat yang salah, pelabelan yang keliru, salah dosis dan salah sediaan.[4] Berdasarkan hasil penelitian menunjukan bahwa implementasi atau penerapan Pelayanan Informasi Obat (PIO) di Apotek Sawojajar termasuk dalam kategori cukup sebanyak $26(52,0 \%)$ dari 50 responden atau pasien Apotek Sawojajar. Dari hasil tersebut menunjukan bahwa implementasi PIO sudah diterapkan dan cukup baik dalam penerapannya kepada pasien di Apotek. Penerapan PIO menjadi salah satu bagian penting dalam pelayanan kefarmasian di Apotek, pelayananan informasi obat menjadi faktor utama dalam penggunaan obat yang baik. [11] Sehingga di Apotek Sawojajar dapat terhindar dari penyalahgunaan obat dengan penerapan dan penyampaian PIO kepada pasien dengan baik. Pasien Apotek menjadi lebih tahu lagi tentang peranan penting dalam penggunaan obat yang pasien konsumsi.

\subsubsection{Kepuasan}

Kepuasan adalah perasaan seseorang yang muncul setelah membandingkan antara kinerja (hasil) produk yang dipikirkan terhadap kinerja (atau hasil) yang diharapkan seperti senang atau kecewa. Apabila kinerja berada dibawah harapan, pasien akan merasa kecewa atau tidak puas. Jika kinerja memenuhi harapan, maka pasien akan merasa senang atau puas. Jika kinerja melebihi harapan, pasien akan merasa sangat puas atau senang. Dasar pertimbangan kepuasan konsumen adalah kesesuaian antara biaya yang dikeluarkan konsumen (cost customer) terhadap nilai barang atau jasa yang didapatkan [12]. Berdasarkan penelitian yang telah dilakukan memberikan hasil bahwa responden yang 
memiliki kepuasan Pelayanan Informasi Obat di Apotek Sawojajar sebanyak 28 (56,0 \%) yang merasa puas, tidak puas $13(26,0 \%)$ dan sangat puas $9(18,0 \%)$. Dari hasil tersebut dapat disimpulkan bahwa pasien di Apotek Sawojajar sebagian besar sudah merasa puas dengan penerapan PIO yang sudah ada di Apotek cukup baik. Oleh karena itu di Apotek juga masih memerlukan pembeharuan dalam penerapan pelayanan informasi obat untuk lebih baik lagi kepada pasien sehingga pasien dapat memperoleh implementasi pelayanan informasi obat dengan baik dan pasien merasa sangat puas.untuk kembali berobat di Apotek Sawojajar.

\subsubsection{Pengaruh Implementasi PIO Terhadap Kepuasan Pasien}

Pelayanan informasi obat bertujuan agar pasien mengetahui penggunaan obat dan bisa meningkatkan tingkat kesembuhan dari penyakit yang diderita oleh pasien yang diterimanya [13]. Berdasarkan hasil penelitian yang telah dilakukan menunjukan bahwa hasil analisis diperoleh nilai $P_{-}$value sebesar $0,024(p<0,05)$ sehingga terdapat hubungan yang signifikan antara implementasi PIO dan kepuasan pasien. Implementasi PIO di dalam Apotek sangatlah penting untuk diterapkan dan disampaikan kepada pasien sehingga memberikan informasi obat yang benar dan tepat dengan menyampaikan isi dari informasi obat seperti nama obat, indikasi atau khasiat, interakasi obat, waktu peminuman obat, cara penyimpanan obat, dan efek samping obat untuk pasien dengan sakit yang berbeda - beda. Implementasi Pelayanan Informasi Obat juga berperan dalam pemilihan obat yang berkualitas, serta cara penggunaan obat yang benar dan tepat terapeutiknya pada pasien sehingga pasien dapat terhindar dari penyalahgunaan obat yang memberikan dampak negatif bagi pasien. Pengaruh imlementasi PIO terhadap kepuasan pasien berperan penting dalam Apotek, semakin baik implementasi PIO dalam Apotek maka akan memberikan kepuasan kepada pasien. Sehingga pasien lebih mengetahui tentang pentingnya peran PIO dalam penggunaan obat, dan pasien juga dapat terhindar dari penyalahgunaan obat dan dampak dari itu. Kepuasan pasien terhadap implementasi PIO dapat memberikan nilai positif bagi Apotek itu sendiri, karena semakin puas pasien dengan pelayanan Apotek maka pasien akan kembali lagi ke Apotek tersebut untuk berobat. Sehingga penghasil Apotek tersebut semakin bertambah.

\section{KESIMPULAN}

Implementasi pelayanan informasi obat (PIO) di Apotek Sawojajar sudah memberikan kepuasan kepada pasien di Apotek Sawojajar sehingga efek negatif dan kejadian yang tidak diharapkan dapat diminimalisasi.

\section{DAFTAR PUSTAKA}

[1] Hanari Fajarini, Implementasi Peraturan Menteri Kesehatan RI No. 73 tahun 2016 Tentang Standar Pelayanan Kefarmasian di Apotek, Jurnal Para Pemikir, Volume 7, Nomor 2, Juni 2018

[2] Endang Sutrisno dan Hanari Fajarini, Legal Culture Of Pharmacist In The Perspective Of Pharmaceutical Services Standard In Pharmacies, Jurnal Dinamika Hukum, Volume 16, Nomor 2, September 2016, page.151

[3] Devi Musfika, Hanari Fajarini, Tya Muldiyana, Evaluasi Obat Non Resep di Apotek Manjur Desa Petunjungan, Jurnal Ilmiah JOPHUS: Journal Of Pharmacy UMUS, Volume 1 Nomor 2, Februari 2020

[4] Handayani, R.S., Raharni, dan Gitawati, R., Persepsi Konsumen Apotek Terhadap Pelayanan Apotek di Tiga Kota di Indonesia, Jurnal Makara Kesehatan, Volume 13 Nomor $1,2009$.

[5] Hanari Fajarini, Apriyanti Ludin, Evaluasi Pelaksanaan Konseling di Apotek Etika Farma Brebes Berdasarkan Permenkes RI Nomor 73 Tahun 2016, Jurnal Sains dan Kesehatan, Volume 2 Nomor 4, November 2020

[6] Azwar, S. 2000. Reabilitas Dan Validitas. Yogyakarta : Pustaka Belajar 
[7] Machfoedz, I. 2005. Metodologi Penelitian Bidang Kesehatan, Keperawatan Dan Kebidanan. Yogyakarta : Fitramaya

[8] Notoatmodjo, S. 2005. Metodelogi penelitian kesehatan. Jakarta : Rineka Cipta.

[9] Sugiyono, DR. 2007. Statistika Untuk Penelitian. Bandung: Alfabeta

[10] Arikunto, S. 2002. Prosedur Penelitian. Jakarta: PT. Rineka Cipta

[11] Yulyuswarni, Profil Pelayanan Informasi Obat Terhadap Pasien dengan Resep Antibiotik di Apotek Kota Bandar Lampung, Jurnal Analis Kesehatan, Volume 6 Nomor 1, Maret 2017

[12] Delladari Mayefis, Auzal Halim, Rida Rahim, Pengaruh Kualitas Pelayanan Informasi Obat Terhadap Kepuasan Pasien Apotek X Kota Padang, Jurnal Ilmu Kefarmasian Indonesia, Volume 13 Nomor 2, September 2015

[13] Resa Setia, Olivia Datu, Jeane Mongi, Yusuf Tapehe, Evaluasi Pelayanan Informasi Obat di Apotek Kecamatan Tikala Kota Manado, Jurnal Biofamasetikal Tropis, Volume 1 Nomor 1, September 2018 